\title{
Intermolecular 2+2 Imine-Olefin Photocycloadditions Enabled by Cu(I)-Alkene MLCT
}

\author{
Daniel M. Flores, Michael L. Neville, and Valerie A. Schmidt*
}

University of California San Diego, Department of Chemistry and Biochemistry, 9500 Gilman Drive, La Jolla, CA, 92093, USA

*Correspondence to: vschmidt@ucsd.edu

\begin{abstract}
Photocycloadditions are idealized, convergent approaches to the construction of 4membered heterocyclic rings, including azetidines. However, methods of direct excitation are limited by the unfavorable photophysical properties of imines and electronically unbiased alkenes. Here, we report copper-catalyzed photocycloadditions of non-conjugated imines and alkenes to produce a variety of substituted azetidines. Ligand design allows this base metal-catalyzed method to achieve $2+2$ imine-olefin photocycloaddition via selective alkene activation through a coordination-MLCT pathway.
\end{abstract}

Nitrogen heterocycles are prevalent motifs in small molecule pharmaceuticals and their rapid construction continues to drive new reaction development. ${ }^{1}$ While 3-, 5- and 6-membered $N$-heterocycles are exceptionally common, made possible by a variety of synthetically accessible routes for their construction, 4-membered heterocycles are scarce by comparison despite the promising biological activity displayed by many azetidine-containing compounds. ${ }^{2,3,4,5,6,7}$ The $2+2$ photocycloaddition of two $\pi$-components is a prototypical approach to 4-membered ring construction. While limited in generality, the Paternò-Büchi reaction forms oxetanes through direct irradiation of a carbonyl $\mathrm{C}=\mathrm{O}$ double bond followed by $\mathrm{C}=\mathrm{C}$ double bond capture. ${ }^{8,9,10}$ Aza-Paternò-Büchi analogs using imines in place of aldehydes or ketones do not generally result in the formation of azetidines due to the low barrier $E / Z$ isomerization available upon excitation of the imine $\mathrm{C}=\mathrm{N}$ double bond. ${ }^{11}$ Maruoka reported a rare intermolecular azetidine-forming $2+2$ photocycloaddition example using naphthyl derived $N$-sulfonyl aldimines and styrene or benzofuran (Figure 1A). ${ }^{12}$ However, this reactivity was exclusive to these substrate pairs and was enabled by a pistacking association of the substrates prior to excitation. Alternative strategies that overcome the challenge of imine isomerization have used cyclic imines which cannot undergo $E / Z$ isomerization, ${ }^{13,14,15}$ via preferential excitation of a conjugated $\mathrm{C}=\mathrm{C}$ double bond tethered to an imine, ${ }^{16,17}$ or both (Figure 1B). Despite these advances, catalyst-controlled approaches to $2+2$ imine-olefin photocycloaddition (IOPC) remain limited as general strategies for azetidine construction. 


\section{A. $\pi$-Stacking pre-organization ${ }^{a}$}

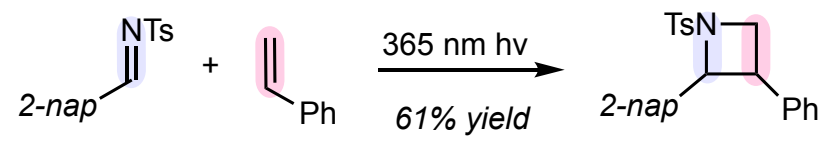

B. Intramolecular $2+2$ photocycloaddition ${ }^{b}$

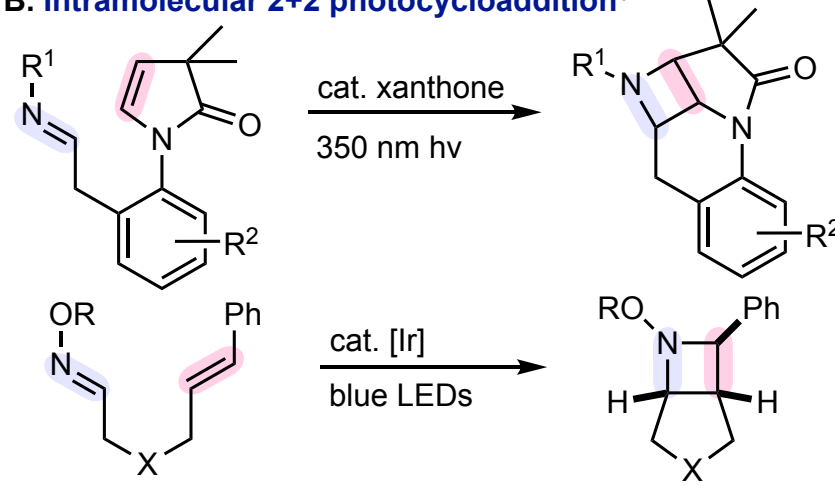

C. Cyclic glyoxylate imine ${ }^{c}$

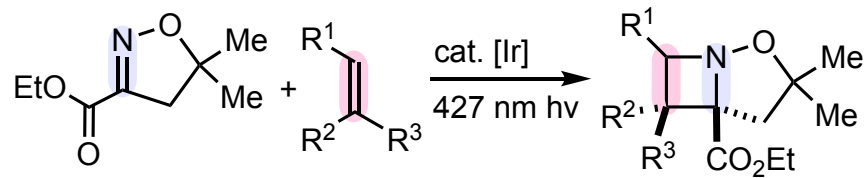

D. Intermolecular imine-olefin $2+2$ (this work):

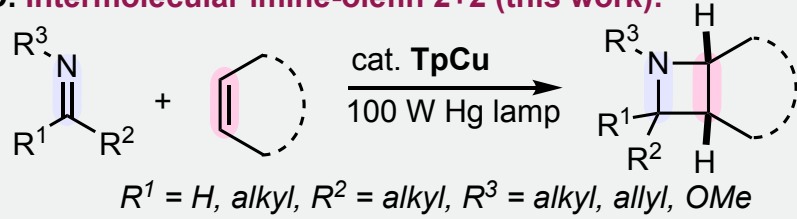

Fig. 1. $\mathrm{C}=\mathrm{N}$ Bond $2+2$ photocycloadditions.

${ }^{a}$ See ref. 12. ${ }^{b}$ See refs. $13-14,16-17 .{ }^{c}$ See ref. 15.

Transition metal compounds capable of photoexcitation via metal to ligand charge transfer (MLCT) to achieve intermolecular electron or energy transfer have recently gained significant recognition for their use in chemical synthesis. ${ }^{18,19,20,21}$ Meggers reported photochemical cyclobutane synthesis by in situ formation of the active chromophore as a chiral at metal, O-bound Rh-enone compound. ${ }^{22}$ Yoon achieved enantioselective $2+2$ photocycloaddition of conjugated alkenes to form cyclobutanes via Dexter energy transfer through H-bonding and $\pi-\pi$ interactions of substrate 3-alkoxyquinolones and Ir-based photocatalysts. ${ }^{23} \mathrm{We}$ recently reported a $\mathrm{Cu}$-catalyzed $2+2$ carbonyl-olefin photocycloaddition approach for oxetane formation by inverting conventional Paternò-Büchi reactivity and achieved alkene activation via coordination followed by MLCT. ${ }^{24}$ We hypothesized that $2+2$ imine-olefin photocycloadditions (IOPC) may be achieved to access azetidines by coordination and MLCT with either the alkene or imine $\pi$ component (Figure 1C). 
To assess this hypothesis, we irradiated a 1:3 mixture of $N$-butyl-2-methylpropan-1-imine (1) and norbornene with catalytic hydrotris(pyrazolyl)borate copper(I) (TpCu) in diethyl ether using a $100 \mathrm{~W} \mathrm{Hg}$ lamp for $8 \mathrm{~h}$ which resulted in formation of the corresponding azetidine $\mathbf{1 A}$ in $31 \%$ yield with exclusive exo selectivity (Table 1, entry 1). Removing either $\mathbf{T p C u}$ or any light source both resulted in no appreciable formation of 1A (entries 2 and 3). Using a small excess of imine relative to norbornene (1.1:1) improved reaction efficiency (entry 4), while using a 3-fold excess of 1, produced 1A in 79\% yield (entry 5). Application of a $300 \mathrm{~nm}$ cut-on filter resulted in a significant decrease in the yield of $\mathbf{1 A}$ to $39 \%$ even after a prolonged $36 \mathrm{~h}$ reaction time suggesting that product forming irradiation occurred at wavelengths shorter than $300 \mathrm{~nm}$ (entry 6). Using $\mathrm{CuCl}$ or CuOTf in place of $\mathbf{T p C u}$ did not result in any detectable quantities of $1 \mathrm{~A}$ (entries 7 and 8), underscoring the importance of the coordination environment of the $\mathrm{Cu}(\mathrm{I})$ source used.

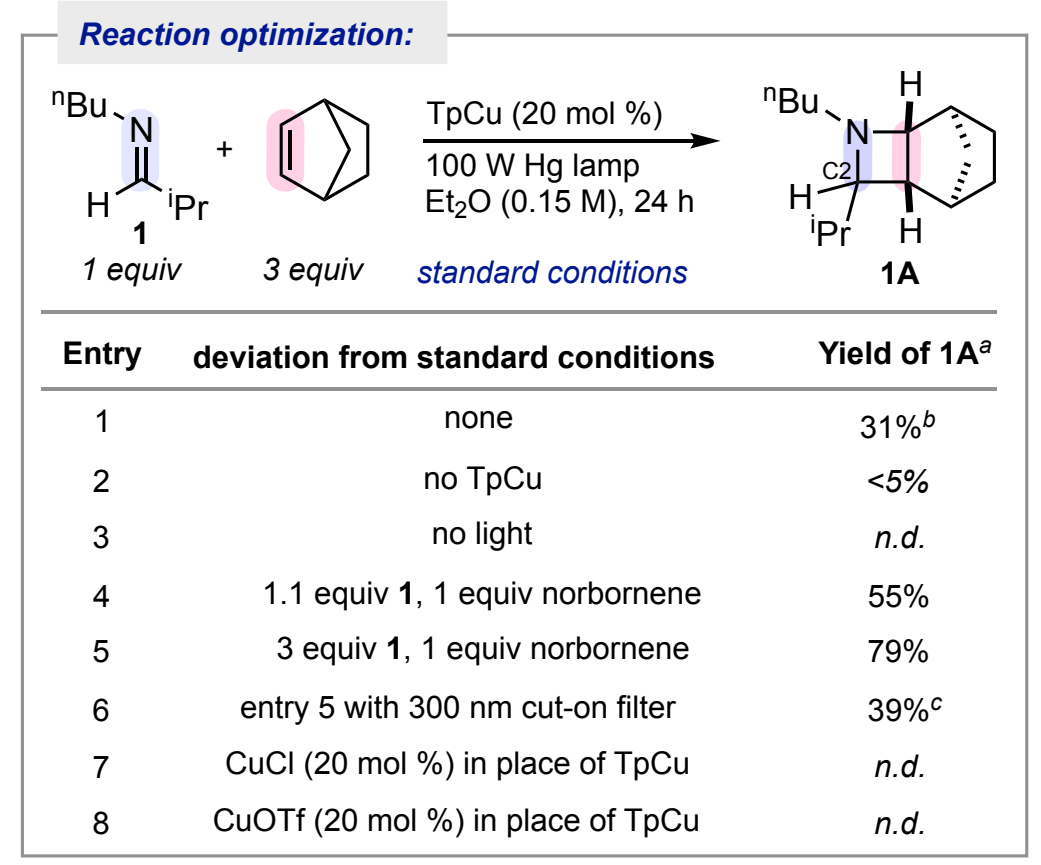

Table 1. Summary of reaction optimization studies.

${ }^{a} \mathbf{1 A}$ was detected as a >95:5 exo:endo mixture and 62:48 diastereomer mixture at $\mathrm{C} 2$ in all experiments; yields determined by ${ }^{1} \mathrm{H}$ NMR analysis of crude reactions using durene as an internal standard. ${ }^{b}$ Reaction time $8 \mathrm{~h}$ due to consumption of $1 .{ }^{c}$ Reaction time $36 \mathrm{~h}$.

In exploration of imines that similarly undergo $\mathrm{Cu}$-catalyzed $2+2$ IOPC with norbornene, we found that aldimines from $N$-allyl amine and isobutyraldehyde, 3-(methylthio)propanal, and melonal all successfully were converted to their corresponding azetidines, $\mathbf{2}, \mathbf{3}$, and $\mathbf{4}$, respectively, in good to excellent yields (Figure 2). Imines bearing cyclopropyl groups participated in this $2+2$ IOPC to produce azetidines exclusively without the detection of cyclopropyl ring-opened products (5 and $\mathbf{6}) \cdot{ }^{25,26}$ While imines derived from acetophenone, benzaldehyde, or aniline did not participate in this $2+2$ IOPC, a phenethylamine derived 
isobutyraldimine, produced azetidine 7 , suggesting that arene groups are tolerated when not conjugated to the imine. Heterocycles including tetrahydrofuran (8), thiophene (9), and morpholine (10) as well as an acyclic $3^{\circ}$ amine (12) were all well tolerated in this process. Productive $2+2$ IOPC was particularly notable in the presence of a $\gamma$-lactam (11), showcasing the chemoselectivity of olefin activation even in the presence of other $\pi$-components capable of absorbing UV light. Imines derived from ketones also reacted efficiently to produce the corresponding azetidines even when the imine also contained Lewis-basic $3^{\circ}$ amine (13), acetal (14), or ether (15) functionalities.
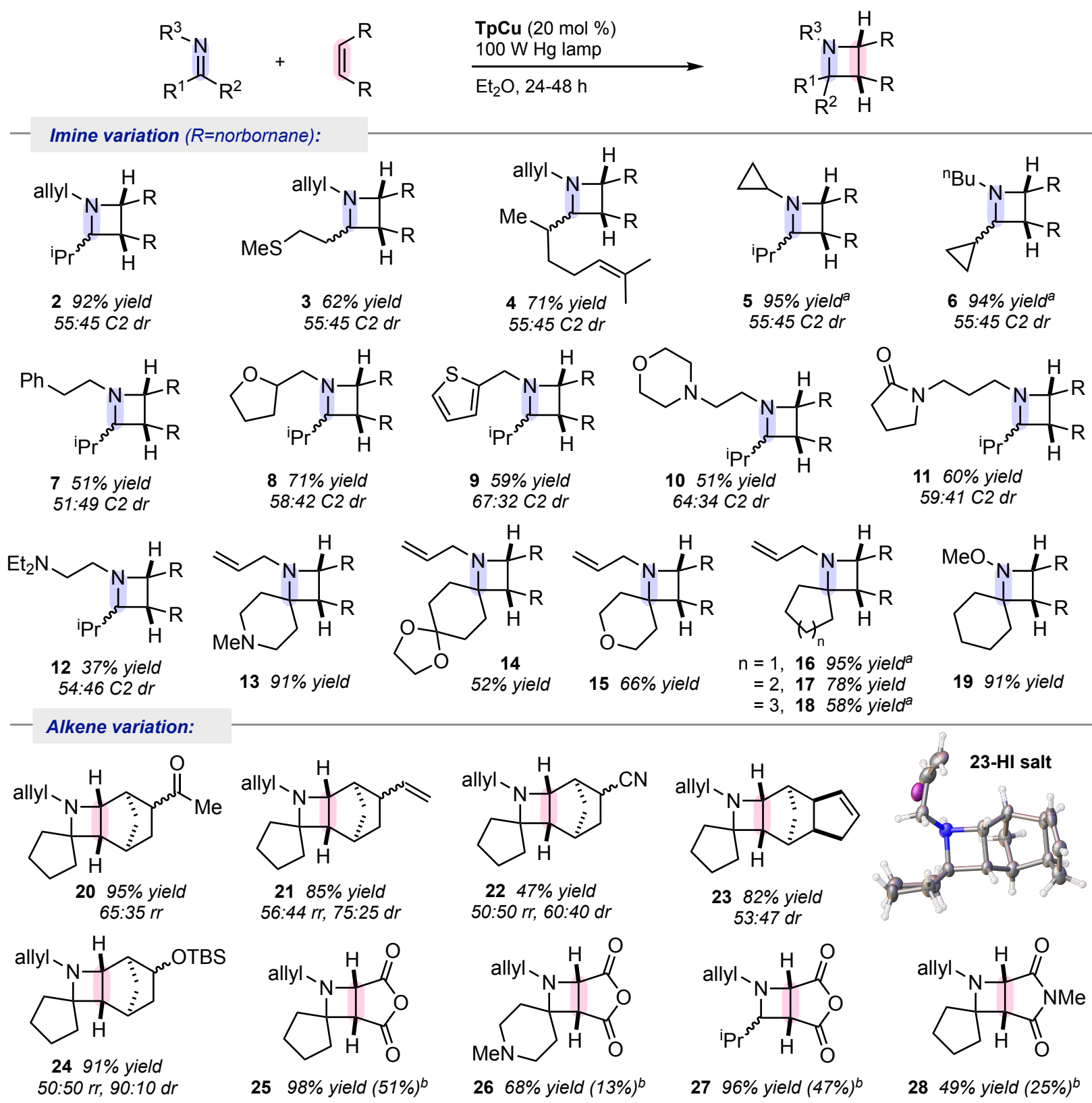

Fig. 2. 2+2 Imine-Olefin photocycloaddition reaction scope.

All reactions carried out with 1 equiv norbornene, 1.1 equiv imine, $20 \mathrm{~mol} \% \mathbf{T p C u}$, in diethyl ether $(0.15$ $\mathrm{M})$ and irradiated with a $100 \mathrm{~W} \mathrm{Hg}$ lamp; all yields are of isolated material following purification via 
basic alumina chromatography and diastereomeric ratios were determined via gas chromatography of crude reaction mixtures; all products detected as $>95: 5$ exo:endo diastereomers. ${ }^{a} 3$ equiv of imine used. ${ }^{b}$ Yield in parentheses obtained without $\mathbf{T p C u}$.

Biologically active azetidines such as penaresidin A, nicotianamine, medicanine, and mugineic acid feature $N$-alkyl groups or are unsubstituted at nitrogen, but access to these $2^{\circ}$ azetidines can be challenging using existing cyclization methods that require $N$-substituents that are stubborn or not amenable to cleavage. This $\mathrm{Cu}$-catalyzed 2+2 IOPC is uniquely capable of engaging $\mathrm{N}$-alkyl imines directly as well as $\mathrm{N}$-substituents that are easily removed. $N$-Allyl azetidine 13 underwent deallylation to reveal the corresponding $2^{\circ}$ azetidine in $82 \%$ yield using $2 \mathrm{~mol} \% \mathrm{Pd}\left(\mathrm{PPh}_{3}\right)_{4}$ and 2-mercaptobenzoic acid. Alternatively, cyclohexanone $O$-methyl oxime also performed well as an imine component in this $2+2 \mathrm{IOPC}$, delivering the corresponding $\mathrm{N}$-methoxy azetidine 19 from which facile reductive $\mathrm{N}-\mathrm{O}$ bond cleavage using activated $\mathrm{Zn}$ dust in aqueous acetic acid to provide the corresponding unsubstituted azetidine in 93\% yield.

Diversification of the olefin component allowed norbornene derivatives containing acetyl, vinyl, cyano, and tert-butyltrimethyl silyl ether groups to be successfully coupled with $N$-allyl cyclopentanimine (20-24). The identity of azetidine $\mathbf{2 3}$ was unambiguously confirmed through determination of the solid-state structure of its hydroiodic salt using X-ray diffraction (Figure 2, 23-HI).

While maleic anhydride is known to undergo selective cyclobutane forming $2+2$ photocycloaddition with ethylene using acetophenone as a photosensitizer, ${ }^{27}$ direct excitation of maleic anhydride with $N$-allyl cyclopentanimine resulted in the formation of azetidine $\mathbf{2 5}$ in $51 \%$ yield along with a complex mixture of unidentified byproducts. Subjecting the same reactant pair to irradiation in the presence of $20 \mathrm{~mol} \% \mathbf{T p C u}$ resulted in the exclusive formation of $\mathbf{2 5}$ in $98 \%$ yield. Similarly, other imines were converted to the corresponding maleic anhydride azetidines (26 and 27) but the use of $\mathbf{T p C u}$ uniformly increased both reaction efficiency and selectivity. $N$-Methyl maleimide was also successfully converted to the corresponding azetidine 29 with $N$-allyl cyclopentanimine in $49 \%$ yield.

We initially hypothesized that $2+2$ IOPC could occur through activation of either the imine or alkene $\pi$ bond; through a combination of ${ }^{1} \mathrm{H}$ NMR and electronic absorption spectroscopies observed the same requirement of alkene coordination to $\mathbf{T p C u}$ for azetidine formation was observed analogously to our $\mathrm{Cu}-$ mediated 2+2 carbonyl-olefin photocycloaddition studies. ${ }^{24} \mathbf{T p C u}-\mathbf{N B}$ was isolated as a white crystalline solid in $87 \%$ yield upon mixing equimolar amounts of $\mathbf{T p C u}$ and norbornene in THF and the solid-state structure determined by single crystal X-ray diffraction (Figure 3A and B). The coordination geometry of the complex is best described as pseudo-tetrahedral about the $\mathrm{Cu}$-ion. The carbon-carbon bond distance of the coordinated olefin $(1.387 \AA)$ is similar to that found in other $\mathrm{Cu}(\mathrm{I})$-norbornene compounds (1.36-1.39 $\AA$ ) indicative of a predominating $\sigma$-bonding, rather than $\pi$-back-bonding, metal-olefin coordination 
interaction. ${ }^{28,29,30,31}$ Examination of the $\mathrm{Cu}-\mathrm{N}$ (pyrazolyl) bond distances reveal that while two were nearly equivalent $(\mathrm{Cu}-\mathrm{N}(2)=1.999(2), \mathrm{Cu}-\mathrm{N}(4)=2.010(2))$, the third was significantly longer $(\mathrm{Cu}-\mathrm{N}(6)=$ $2.274(2)$ ), breaking the $\mathrm{C}_{3}$ symmetry axis of the hydrotris(pyrazolyl)borate chelate.

\section{A. Olefin complex synthesis}

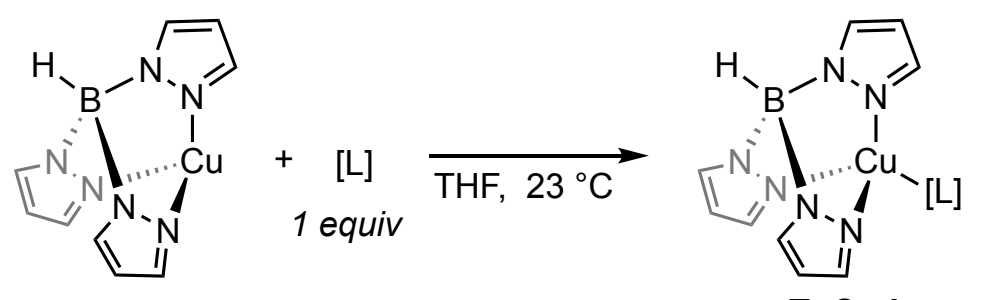

$$
1 \text { equiv }
$$

$[\mathrm{L}]=$ norbornene $(\mathrm{NB}), 87 \%$ yield

TpCu-L

\section{B. X-Ray structures}

$=$ maleic anhydride (MA), 93\% yield

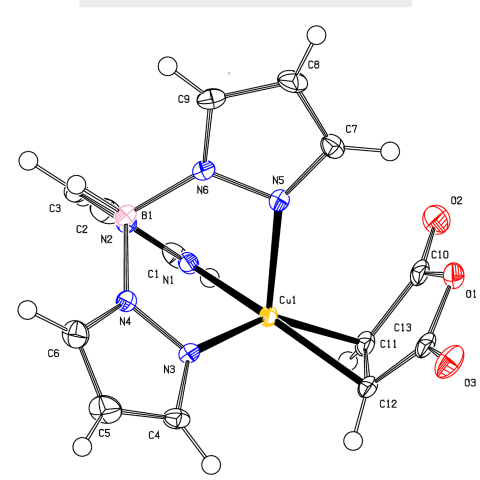

TpCu-MA

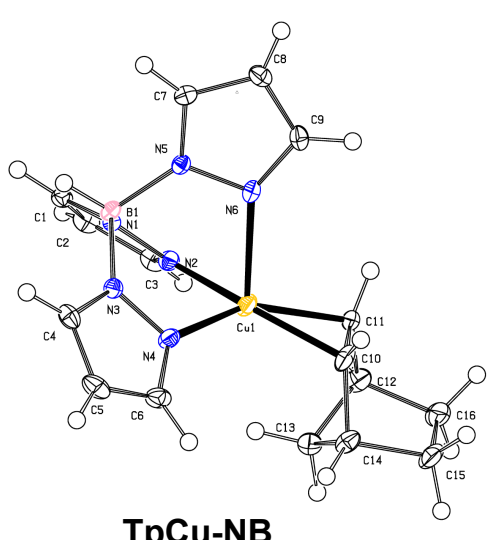

TpCu-NB

\section{Electronic absorption spectra}

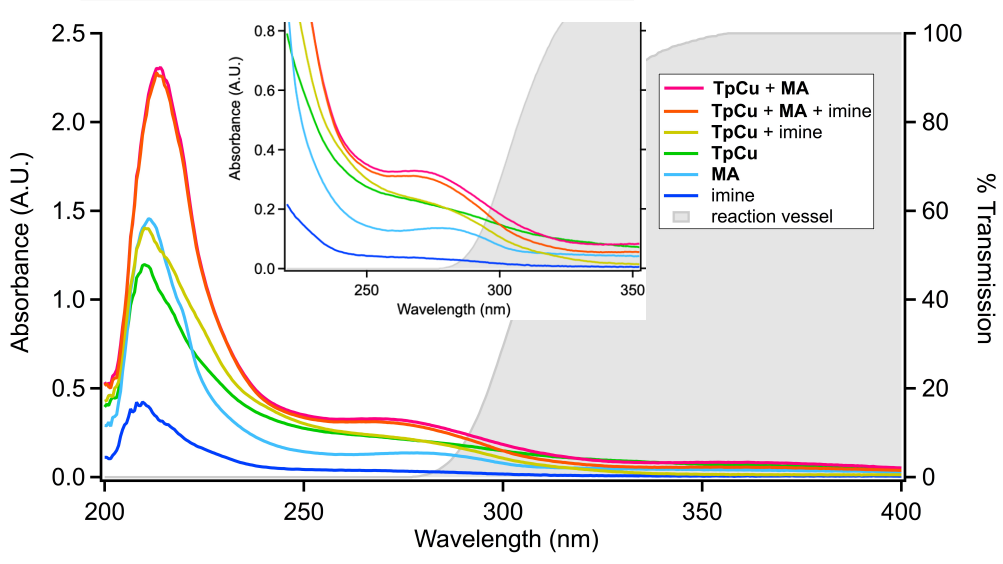

Fig. 3. Spectroscopic investigations of $2+2$ IOPC reaction intermediates.

A. Synthesis of hydrotris(pyrazolyl)borate copper olefin compounds. B. X-ray structures of the norbornene and maleic anhydride complexes TpCu-NB and TpCu-MA. C. Electronic absorption spectra of reaction components and transmission spectrum of reaction vessels used. 
The maleic anhydride adduct, TpCu-MA, was similarly prepared and crystallographically characterized. The coordination geometry of the complex is analogous to that of $\mathbf{T p C u}-\mathbf{N B}$ and while the carbon-carbon bond length of the coordinated maleic anhydride $(1.390 \AA)$ is elongated compared to the free olefin (1.3032 $\AA),{ }^{32}$ it is short compared to the only other structurally characterized $\mathrm{Cu}(\mathrm{I})$-maleic anhydride compound which is supported by an iminophosphanamide chelate $(1.49 \AA),{ }^{33}$ suggesting that the bonding in $\mathbf{T p C u} \mathbf{p}$ MA is analogous to that observed in TpCu-NB. While ligand exchange was observed by ${ }^{1} \mathrm{H}$ NMR spectroscopy from TpCu-NB in the presence of the imines used in our study, isolation of a TpCu-imine coordination compound was unsuccessful likely due to the observed rapid ligand exchange. However, coordinated maleic anhydride was not analogously displaced by imines of this study, facilitating further mechanistic investigations with this system.

The electronic absorption spectra of ethereal solutions of individual 2+2 IOPC reaction components showed no distinct absorption features $250-400 \mathrm{~nm}$ and the transmission spectrum of the borosilicate glass reaction vessels used in this study indicated that light below $280 \mathrm{~nm}$ is largely filtered from reaching the reaction mixture (Figure 3C). Combined with the $300 \mathrm{~nm}$ cut-on filter results (Table 1, entry 6), this supports that azetidine formation predominately occurs via excitation between $280-300 \mathrm{~nm}$. Conversely, a stoichiometric solution mixture of $\mathbf{T p C u}$ and maleic anhydride resulted in an electronic absorption spectrum with a broad feature with a maximum at $263 \mathrm{~nm}$, which is very similar to the spectrum observed of TpCu-NB and is nearly identical to the spectrum of a stoichiometric mixture of $\mathbf{T p C u}$, maleic anhydride and imine $\mathbf{1}$. While neither 1 nor norbornene showed significant absorptions above $250 \mathrm{~nm}$, maleic anhydride did, rationalizing the small amount of non-catalyzed background photocycloaddition observed with this alkene. 


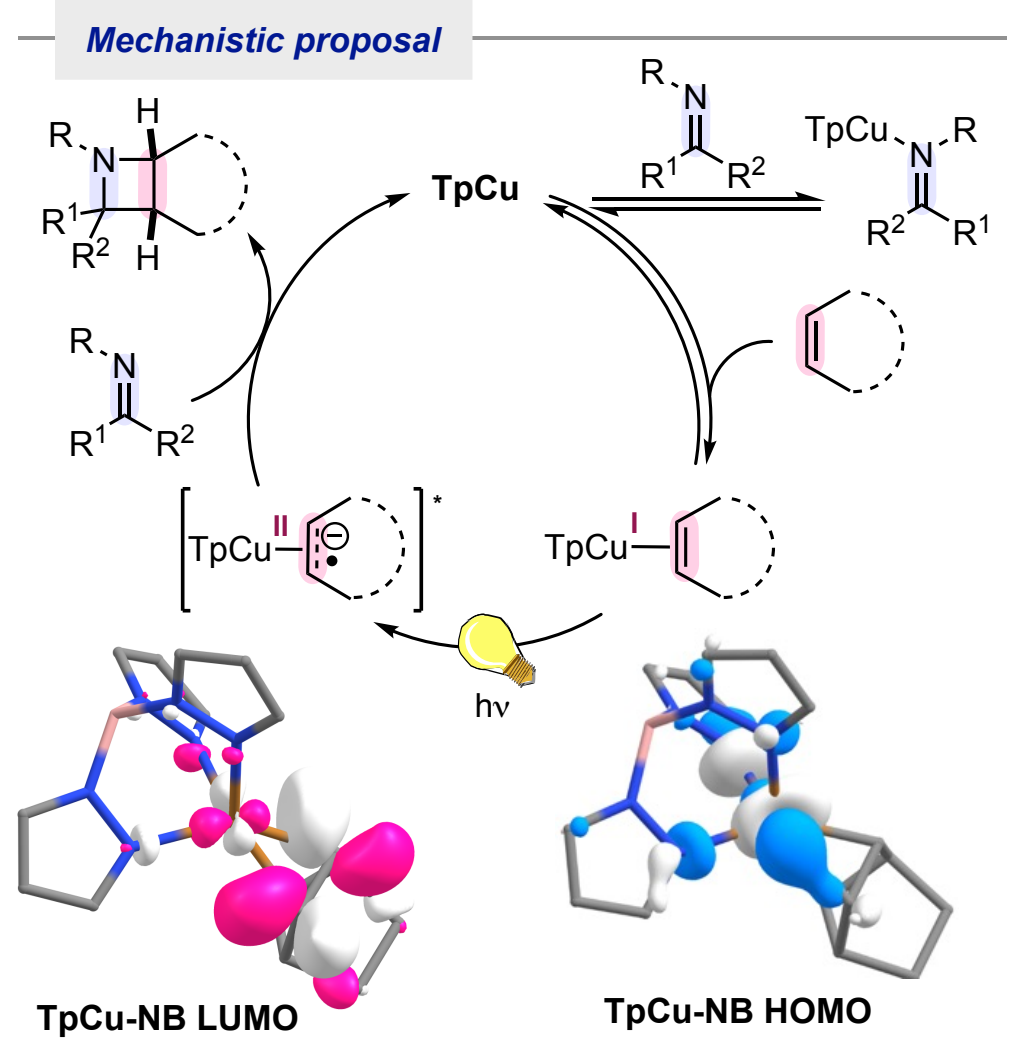

Fig. 4. 2+2 IOPC mechanistic proposal

A calculated electronic absorption spectrum of TpCu-NB best approximated the experimentally observed spectrum using time-dependent density functional theory (DFT) calculations of at the M06 level of theory with the Tamm-Dancoff approximation. This enabled the construction of qualitative molecular orbital diagrams for TpCu-NB at the observed absorption feature 250-300 nm linked to azetidine formation (see the Supporting Information for additional details). The highest occupied molecular orbital (HOMO) and the lowest unoccupied molecular orbital (LUMO) of TpCu-NB are primarily $\mathbf{T p C u}$-based and olefin( $\left(\pi^{*}\right)$ based, respectively (Figure 4). This is supported by prior DFT calculations that concluded that MLCT of idealized cationic $\mathrm{Cu}(\mathrm{I})$-ethylene compounds was responsible for cyclobutane forming $2+2$ photocycloadditions. ${ }^{34}$ This excited state selectively then captures the imine $\mathrm{C}=\mathrm{N}$ group affording the azetidine product. Chemoselectivity of azetidine formation over alkene dimerization pathways is attributed to the known rapid rates of $\mathrm{C}$-centered radical addition to $\mathrm{C}=\mathrm{N}$ double bonds ${ }^{35}$ and preference over alkene addition. $^{25}$

In conclusion, we report herein an intermolecular $2+2$ photocycloaddition of aliphatic imines and alkenes to form azetidines. The use of hydrotris(pyrazolyl)borate copper(I) as a pre-catalyst allows for coordination of the olefin component and selective absorption of light $280-300 \mathrm{~nm}$. A combination of solution ${ }^{1} \mathrm{H}$ NMR 
and electronic absorption spectroscopies along with DFT calculations from solid-state structural information supports that $\mathrm{Cu}(d)$ to olefin $\left(\pi^{*}\right)$ MLCT leads to azetidine formation. This work highlights a catalyst controlled $2+2$ imine-olefin photocycloaddition strategy that selectively activates $\pi$-components at red-shifted wavelengths compared to uncoordinated substrates.

\section{Acknowledgments}

We thank Christine Lee and Jacob Hawver-Patcher for preliminary assistance in imine synthesis, the Tor group at UCSD for usage of their UV-vis spectrometer, and Glen Junor for assistance with DFT calculations.

\section{Funding}

This work was supported by start-up funds provided by the University of California San Diego, National Science Foundation CAREER Award No. 1945463, and the American Chemical Society Petroleum Research Fund grant 60135-DNI1.

\section{Author contributions}

D.M.F. carried out the synthetic work, analytical characterization, spectroscopic and computational studies. M.L.N. carried out the crystallographic studies. V.A.S. assisted with data analysis and directed the research. V.A.S. wrote and edited the manuscript, with input from all authors.

\section{Competing interests}

Authors declare no competing interests.

\section{Data and materials availability}

X-ray data are available free of charge from the Cambridge Crystallographic Data Centre under references CCDC-1986944 (23-HI), CCDC-1986945 (TpCu-NB), CCDC-1986946 (TpCu-MA). Additional synthetic, spectroscopic, crystallographic, and computational data are included in the supplementary materials.

\section{References}

${ }^{1}$ Vitaku, E.; Smith, D. T.; Njardarson, J. T. Analysis of the Structural Diversity, Substitution Patterns, and Frequency of Nitrogen Heterocycles among U.S. FDA Approved Pharmaceuticals. J. Med. Chem. 2014, 57, 10257 - 10274. DOI: 10.1021/jm501100b.

${ }^{2}$ Brandi, A.; Cicchi, S.; Cordero, F. M. Novel Syntheses of Azetidines and Azetidinones. Chem. Rev. 2008, 108, 3988-4035. DOI: 10.1021/cr800325e.

${ }^{3}$ Mehra, V.; Lumb, I.; Anand, A.; Kumar, V. Recent advances in synthetic facets of immensely reactive azetidines. $R S C A d v$. 2017, 7, 45763-45783. DOI: 10.1039/C7RA08884A.

${ }^{4}$ Antermite, D.; Degennaro, L.; Luisi, R. Recent advances in the chemistry of metallated azetidines. Org. Biomol. Chem. 2017, 15, 34-50. DOI: 10.1039/C6OB01665K.

${ }^{5}$ Behnke, N. E.; Lovato, K.; Yousufuddin, M.; Kürti, L. Titanium-Mediated Synthesis of Spirocyclic NHAzetidines from Oxime Ethers. Angew. Chem. Int. Ed. 2019, 58, 14219-14223. DOI: 10.1002/anie.201909151. ${ }^{6}$ Bondada, L.; Rondla, R.; Pradere, U.; Liu, P.; Li, C.; Bobeck, D.; McBrayer, T.; Tharnish, P.; Courcambeck, J.; Halfon, P.; Whitaker, T.; Amblard, F.; Coats, S. J.; Schinazi, R. F. Azetidines and spiro azetidines as novel P2 units in hepatitis C virus NS3 protease inhibitors. Bioorg. Med. Chem. Lett. 2013, 23, 6325-6330. DOI: 10.1016/j.bmcl.2013.09.068. 
${ }^{7}$ Kirichok, A. A.; Shton, I. O.; Pishel, I. M.; Zozulya, S. A.; Borysko, P. O.; Kubyshkin, V.; Zaporozhets, O. A.; Tolmachev, A. A.; Mykhailiuk, P. K. Synthesis of Multifunctional Spirocyclic Azetidines and Their Application in Drug Discovery. Chem. Eur. J. 2018, 24, 5444-5449. DOI: 10.1002/chem.201800193.

${ }^{8}$ Griesbeck, A. G. In Molecular and Supramolecular Photochemistry; Griesbeck, A. G., Mattay, J., Eds.; Marcel Dekker: New York, 2005; Vol. 12: Synthetic Organic Photochemistry, Chapter 4.

${ }^{9}$ Scharf, D.; Korte, F. Photosensibilisierte cyclodimerisierung von norbornen. Tetrahedron Lett., 1963, 13, 821-823. DOI: 10.1016/S0040-4039(01)90722-1.

${ }^{10}$ Arnold, D. R.; Hinman, R. L.; Glick, A. H. Chemical properties of the carbonyl n, $\pi$ state. The photochemical preparation of oxetanes. Tetrahedron Lett., 1964, 5, 1425 - 1430. DOI: 10.1016/S00404039(00)90493-3.

${ }^{11}$ Padwa, A. Photochemistry of the carbon-nitrogen double-bond. Chem. Rev. 1977, 77, 37 - 68. DOI: 10.1021/cr60305a004.

${ }^{12}$ Sakamoto, R.; Inada, T.; Skaurai, S.; Maruoka, K. [2+2] Photocycloadditions between the Carbon-Nitrogen Double Bonds of Imines and Carbon-Carbon Double Bonds. Org. Lett. 2016, 18, 6252 - 6255. DOI: 10.1021/acs.orglett.6b03003.

${ }^{13}$ Swenton, J. S.; Hyatt, J. A. Photosensitized cycloadditions to 1,3-dimethyl-6-azauracil and 1,3-dimethyl-6azathymine. Imine linkage unusually reactive toward photocycloaddition. J. Am. Chem. Soc. 1974, 96, 4879 4885 .

${ }^{14}$ Howard, K. A.; Koch, T. H. Photochemical reactivity of keto imino ethers. V. (2+2) Photocycloaddition to the carbon-nitrogen double bond of 3-ethoxyisoindolone. J. Am. Chem. Soc. 1975, 97, $7288-7298$.

${ }^{15}$ Becker, M. R.; Wearing, E. R.; Schindler, C. S. Synthesis of azetidines via visible-light-mediated intermolecular [2+2] photocycloadditions. Nature Chem. 2020, 12, 898-905. Doi: 10.1038/s41557-020-0541-1. ${ }^{16}$ Kumarasamy, E.; Kandappa, S. K.; Raghunathan, R.; Jockushch, S.; Sivaguru, J. Realizing an Aza PaternòBüchi Reaction. Angew. Chem. Int. Ed. 2017, 56, 7056 - 7061.

${ }^{17}$ Becker, M. R.; Richardson, A. D.; Schindler, C. S. Functionalized Azetidines Via Visible Light-Enabled Aza Paternò-Büchi Reactions. Nat. Commun. 2019, 10, 5095. DOI: 10.1038/s41467-019-13072-x.

${ }^{18}$ Narayanam, J. M. R.; Stephenson, C. R. J. Visible light photoredox catalysis: applications in organic synthesis. Chem. Soc. Rev. 2011, 40, 102 - 113. DOI: 10.1039/B913880N.

${ }^{19}$ Prier, C. K.; Rankic, D. A.; MacMillan, D. W. C. Visible Light Photoredox Catalysis with Transition Metal Complexes: Applications in Organic Synthesis. Chem. Rev. 2013, 113, 5322 - 5363. DOI: 10.1021/cr300503r.

${ }^{20}$ Shaw, M. H.; Twilton, J.; MacMillan, D. W. C. Photoredox Catalysis in Organic Synthesis. J. Org. Chem. 2016, 81, 6898 - 6926. DOI: 10.1021/acs.joc.6b01449.

${ }^{21}$ McAtee, R. C.; McClain, E. J.; Stephenson, C. R. J. Illuminating Photoredox Catalysis. Trends in Chemistry 2019, 1,111 - 125. DOI: 10.1016/j.trechm.2019.01.008.

${ }^{22}$ For a chiral at metal example of cyclobutane forming $2+2$ photocycloaddition, see: Huang, X.; Quinn, T. R.; Harms, K.; Webster, R. D.; Zhang, L.; Wiest, O.; Meggers, E. Direct Visible-Light-Excited Asymmetric Lewis Acid Catalysis of Intermolecular [2+2] Photocycloadditions. J. Am. Chem. Soc. 2017, 139, 9120 - 9123. DOI: $10.1021 /$ jacs. 7 b04363.

${ }^{23}$ Daub, M. E.; Jung, H.; Lee, B. J.; Won, J.; Baik, M.-H.; Yoon, T. P. Enantioselective [2+2] Cycloadditions of Cinnamate Esters: Generalizing Lewis Acid Catalysis of Triplet Energy Transfer. J. Am. Chem. Soc. 2019, 141, 9543 - 9547. DOI: $10.1021 /$ jacs.9b04643.

${ }^{24}$ Flores, D. M.; Schmidt, V. A. Intermolecular 2+2 Carbonyl-Olefin Photocycloadditions Enabled by Cu(I)Norbornene MLCT. J. Am. Chem. Soc. 2019, 141, 8741 - 8745. DOI: 10.1021/jacs.9b03775.

${ }^{25}$ Fallis, A. G.; Brinza, I. M. Free radical cyclizations involving nitrogen. Tetrahedron 1997, 53, 17543-17594.

${ }^{26}$ H. Togo, "1 - What are Free Radicals?" in Advanced Free Radical Reactions for Organic Synthesis (Elsevier, San Diego, CA, 2004), p. 29.

${ }^{27}$ Hernvann, F.; Rasore, G.; Declerck, V.; Aitken, D. J. Stereoselective intermolecular [2+2]photocycloaddition reactions of maleic anhydride: stereocontrolled and regiocontrolled access to 1,2,3trifunctionalized cyclobutanes. Org. Biomol. Chem. 2014, 12, 8212-8222. DOI: 10.1039/C4OB01383B.

${ }^{28}$ Xiaohua, B.; Holt, E. M. Copper(I) halide complexation to norbornene: $(\mathrm{CuCl})_{5}$ (norbornene) 4 : A complex of novel structure. J. Crystallographic and Spectroscopic Research 1990, 20, 339-345. DOI:

10.1007/BF01274141. 
${ }^{29}$ Michon, C.; Medina, F.; Capet, F.; Roussel, P.; Agbossou-Niedercorn, F. Inter- and Intramolecular Hydroamination of Unactivated Alkenes Catalyzed by a Combination of Copper and Silver Salts: The Unveiling of a Brønstedt Acid Catalysis. Adv. Synth. Catal. 2010, 352, 3293-3305. DOI:

$10.1002 /$ adsc. 201000536.

${ }^{30}$ Pasquali, M.; Floriani, C.; Gaetani-Manfredotti, A.; Chiesi-Villa, A. Interaction of an aliphatic carbonhydrogen bond with copper in a norbornene(diethlenetriamine)copper(I) cation complex. J. Am. Chem. Soc. 1978, 100, 4918-4919. DOI: 10.1021/ja00483a061.

${ }^{31}$ Straub, B. F.; Eisenträger, F.; Hofmann, P. A remarkably stable copper(I) ethylene complex: synthesis, spectroscopy and structure. Chem. Commun. 1999, 2507-2508. DOI: 10.1039/a907928i.

${ }^{32}$ Marsh, R. E.; Ubell, E.; Wilcox, H. E. The crystal structure of maleic anhydride. Acta. Cryst. 1962, 15, 3541. DOI: $10.1107 / \mathrm{S} 0365110 X 62000080$.

${ }^{33}$ Straub, B. F.; Gruber, I.; Rominger, F.; Hofmann, P. Mechansim of copper(I)-catalyzed cyclopropanation: a DFT study calibrated with copper(I) alkene complexes. J. Organomet. Chem. 2003, 684, 124-143. DOI: 10.1016/S002-328X(03)00520-5.

${ }^{34}$ Budzelaar, P. H. M.; Timmermans, P. J. J. A.; Mackor, A.; Baerends, E. J. Bonding in the ground state and excited states of copper-alkene complexes. J. Organomet. Chem. 1987, 331, 397-407. DOI: 10.1016/0022328X(87)80011-6.

${ }^{35}$ Friestad, G. K. Addition of carbon-centered radicals to imines and related compounds. Tetrahedron 2001, 57, 5461-5496. 